\title{
Audit
}

\section{A guide for the trainee}

\author{
Danny Allen, Senior Registrar, Fromeside Clinic, Blackberry Hill, Stapleton, \\ Bristol BS16 1ED
}

Audit is certainly the topic of the moment. It is much talked about and a lot of money is being made available for it, yet it seems that there are few real guidelines about how to do it. Many junior doctors who would like to do audit may be put off by the computers and other paraphernalia which are deemed necessary for this purpose. While technology can help, it is by no means necessary and some of the best audit follows the same principles as research: keep it simple.

The College (1989) has produced a preliminary report on audit in which the point is made that quality is at least as important as quantity. It is also far more interesting to many staff who, in my experience, feel that they are able to improve their practice, as opposed to quantitative audit which may easily be seen as a tool of management to improve productivity.

The model which I would recommend to the trainee or senior registrar embarking upon audit for the first time would be that developed by the team at the Royal South Hants Hospital (Edwards et al, 1987). They started off with case-note review and developed a system of audit meetings which stood the test of time. It is a similar system to that which is described by James (1992) as applied to a regional secure unit.

This article describes my experience in a day hospital but the methods described can easily be adapted to any setting.

\section{How to get started}

The first thing that is needed is enthusiasm. In my case I was allocated a number of sessions at the day hospital without a particular brief. I was interested in audit and suggested to my consultant that I devoted a proportion of my time to it. I was given the go-ahead but from then on all enquiries aimed at establishing what the audit should be about or what form it should take were met with obscure comments about someone in the library being an expert on computers! The good news for trainees who are not especially computer literate was that my audit was achieved without the use of computers, although they are a useful adjunct for those who want to use them.
The trainee interested in setting up an audit programme will probably best act as a facilitator. I used the beginning of my time at the day hospital to talk about audit and gauge people's reactions to it. If you are keen enough, staff should be willing to donate the next vital component: time. There is no point in being over-ambitious; an hour a month, perhaps in a preexisting slot, occupied by a case-conference or similar meeting, is all that is needed Any more can lead to complaints, unfulfilled expectations and the demise of the programme although, of course, a little more time is needed by the facilitator.

The next decision is who is to be involved. Medical audit means just doctors; clinical audit can involve the whole team. In our case there was little debate, the nature of a day hospital clearly lends itself to a multidisciplinary approach but consideration may need to be given to whether this is always appropriate in other settings. One compromise might be to alternate depending on the subject of the audit; this would be especially important if the discussion would tend to exclude other staff by its very nature - e.g. blood tests. Keeping staff interest is paramount.

The next step is to have the inaugural meeting. As far as possible staff should be prepared to come with ideas for audit but as the concept will be new to some, do not expect instant success; it is enough that people show up and express interest. The facilitator's job at this meeting will be to explain what audit, as envisaged here, is about. It is just as important to state what it is not about, i.e. checking how much work people are doing or trying to analyse the nature of that work. Personal experience indicates that this sort of 'managerial' audit is excellent at getting people's backs up and achieves nothing of use. It depresses morale as opposed to raising it as qualitative audit can do.

The point that needs to be made at the first meeting is that audit is a means by which professionals can set standards and see how well they perform by their own lights. This latter part is very important, as it gives a feeling of control to the staff, and rightly so. After this subject has been discussed more than half the meeting will probably have passed and it is time to brainstorm. Ideas for audit are likely to be 
forthcoming. If not, the facilitator can inject some of their own, perhaps using examples from this article!

When the ideas have run dry a tentative agenda for the second meeting is set and a definite date and time established.

\section{The first audit meeting}

About a week before the meeting the facilitator should produce a brief agenda, he or she should then go about reminding people and enthusing them. Personal experience suggests that one simple topic per meeting is adequate. One usually gets through less than one sets out to at first and it is always better to finish a meeting early and postpone discussion than to beat out poor ideas in the last five minutes. This does not matter at all, because it is possible to have a rolling agenda and people know that they will have a chance to discuss things later. So what sort of things do people want to discuss? The topics which we started with were communication with GPs, prescribing, recording attendance, client review, and handling information.

Obviously there is nothing special about these topics, but they were the result of what staff were interested in. Other topics fell by the wayside as it was felt there was little practical purpose in discussing them. Sometimes the topic audited bore little resemblance to the original idea.

The most important point when the subject has been discussed is to formulate the aims in an auditable fashion. This means two things: first, the aim should be $100 \%$ success. Knowing one will reach it does not allow one to aim at less. Second, the aims must be checkable. Information recording methods must be established clearly at the meeting or by named persons before the next meeting. To do less is to court failure. For example, we agreed that appointment notes, assessment letters, six monthly notes and outcome letters would be sent to GPs. In order to check this we had to institute a recording system; the original idea proved impractical so it was modified at the next meeting.

Before closing it is important to make sure everyone knows what is to be discussed next month and finally agree a time interval after which you will return to check that month's audit. Simplicity dictates that this should be the same for all topics and a suggested interval is six months.

After the meeting it is the facilitator's duty to produce a sheet of audit aims, to be circulated, posted and preferably placed in a central recording mechanism for posterity. The sheet should explain the principles of audit: aim for $100 \%$ success, review in $x$ months, and alter standards or practice accordingly thereafter.

\section{The second audit meeting}

The agenda for this meeting should contain three sections: audit topic of the month, revisions to last month's audit, and suggestions for next month's audit.

Again the agenda must go out in time to jog people's memories and get them thinking about the topics. The second section is important because often the practicalities of implementing last month's audit may not have been as straightforward as expected and modifications may be necessary.

\section{The seventh audit meeting}

Assuming a six month review cycle as suggested above, it is now time to go back to reviewing the first month's audit aim. It is to be hoped your team will have now become adept at formulating aims within half an hour so in theory there should be plenty of time for review! In practice, the first one or two reviews may well be a bit traumatic as people have forgotten what it was all about so it may be wise to suspend the formulation section of your meeting and concentrate on review.

It is important to establish that staff understand that they are not being criticised and care should be taken to avoid personalisation. Where standards fall short of the aims, as they invariably will, people should decide whether this is due to bad practice, poor recording or other errors or whether there is an inherent flaw in the aims and therefore whether the standard should be redesigned.

At this stage it is important that clear conclusions are reached otherwise the whole exercise may be seen as a waste of time. It is the job of the facilitator to attempt to draw together the threads of the argument and to try to salvage some modicum of logic from what can easily become a free-floating discussion.

It is important not to become discouraged. Auditing is a skill which it takes a team some time to learn. There may well be low points, particularly at the review, but it is important to plough on as staff will gradually understand the significance of "closing the audit loop' and recording practice for future audit will gradually become part of normal working practice.

\section{Keeping going}

It is in the nature of the job that trainees move on. But it is important to give a thought to continuity. It is to be hoped that you will have generated enthusiasm among other staff and that one of them will be keen to take on your mantle - perhaps another trainee, or, more permanently, a clinical assistant or member of the nursing staff. Whichever way, if it has been worth doing it will be worth continuing. After a while staff will hopefully look upon audit, not as some academic exercise imposed upon them by doctors, but as a tool which everyone can use to improve standards. 


\section{References}

EdWARds, J. G., NunN, C. M. H. \& RicketTs, B. S. (1987) Three years of medical audit in a psychiatric unit. Bulletin of the Royal College of Psychiatrists, 11, 154-155.
JAmEs, A. (1992) Practical experience from a regional secure unit. Psychiatric Bulletin, 16, 84-85.

The Royal College of Psychiatrists (1989) Working Party from Council. Preliminary report on medical audit. Psychiatric Bulletin, 13, 577-580.

\title{
The quality of computerised tomography use in two psychogeriatric services
}

\author{
JoN SPEAR, Research Registrar, St Nicholas Hospital, Gosforth, Newcastle upon Tyne \\ NE3 3XT
}

The aim of medical audit is to improve the quality of medical care (Department of Health, 1989). There was concern that patients referred to a psychogeriatric service (Service $\mathrm{X}$ ) did not have adequate access to computerised tomography. The nearest computerised tomography scanner was located in a neighbouring district and direct referrals were not accepted. Computerised tomography scans could be obtained indirectly by referral to neurosurgeons. Because of these difficulties "potentially treatable structural lesions" (such as cerebral tumours and subdural haematomas) may have been missed. We decided to compare the use of computerised tomography scans with a nearby service (Service $Y$ ) which had a computerised tomography scanner on site. Service $X$ had a catchment population of 33,000 aged over 65 and Service $Y$ a catchment population of 23,420 aged over 65.

Weinberger (1984) has suggested the following indications for CT scans for elderly psychiatric patients:

(a) confusion or dementia of unknown cause

(b) first episode of psychosis of major depressive episode

(c) prolonged catatonia

(d) personality change.

In a study of patients with confusion or dementia 36 out of $331(10.9 \%)$ had potentially treatable lesions identified by CT scanning (Roberts \& Caird, 1990). Risk factors which increase the probability of "potentially treatable lesions" in elderly patients with confusion or dementia are focal neurological signs, headaches, papilloedema, epilepsy (Bradshaw et al, 1983), reduced alertness and a duration of less than one year (Roberts \& Caird, 1990).

\section{The study}

All patients in service $X$ and service $Y$ referred in 1990 and who had computerised tomography head scans were included. Fifty controls were randomly selected from patients referred to service $Y$ in 1990. Information from case-notes was recorded on a proforma.

\section{Findings}

Patients referred to Service $Y$ were more likely to have a computerised tomography scan $(21 / 222 \mathrm{v}$. $10 / 449 ; \chi=16 ;$ d.f. $=1 ; P<0.001$ ) than patients referred to Service $Y$. Patients who had computerised tomography were younger than controls (72.1 years v. 78.5 years; $t=2.4 ; P<0.05)$. Most patients who had computerised tomography were male $(18 / 31)$ while most controls were female $(38 / 50 ; P<0.01)$.

All patients who had computerised tomography scans had an indication. For Service $X$ these were confusion (6) and dementia (4). For service $Y$ the indications were confusion (4), dementia (11), first onset psychosis (5) and personality change (1). There was no difference in the frequency of risk factors between Service $X(9 / 10)$ and Service $Y(17 / 21)$. Nine patients $(29 \%)$ had focal neurological signs; of these four had cerebral infarcts, two atrophy and three had potentially treatable lesions (a meningioma, a subdural haematoma and normal pressure hydrocephalus). Focal neurological signs were a predictor of "potentially treatable lesions" (Fisher's Exact Test; $P=0.008$ ). Twenty-two patients did not have focal neurological signs; of these nine had infarcts, 11 atrophy and two were "normal". All three patients with "potentially treatable lesions" were from Service X. 